\title{
Beyond New Public Management: Answering the Claims of Both Politics and Society
}

\author{
PETER NOORDHOEK \\ Northedge, The Netherlands \\ RAYMOND SANER \\ CSEND, Switzerland
}

dpn@northedge.nl

saneryiu@csend.org and saner@csend.org

Key words: New Public Management, organization, public sector, benchmarking, culture clash, trust, total quality management

\begin{abstract}
New Public Management held the promise of changing traditional bureaucracies into a resultsoriented and transparent form of government. Though many of the principles of NPM are being implemented as a way of thinking about government it has been largely discredited. This paper gives examples from Switzerland and The Netherlands where the premises of NPM have either explicitly or implicitly been rejected. The paper concludes by suggesting reasons that led to the decline of NPM and concludes by offering a 'conceptual restart' of public administrative reform. This is based on a constructive mix between aspects of NPM and traditional administration, leading to a New Public Administration.
\end{abstract}

\section{Introduction}

New Public Management held the promise of changing traditional bureaucracies into a results-oriented and transparent form of government, directed and supported by efficient and effective public managers. Though many of the principles of NPM are being implemented in many parts of the world, NPM as a way of thinking about government has been largely discredited. This paper gives examples from Switzerland and The Netherlands where the premises of NPM have either explicitly or implicitly been rejected, in the case of Switzerland by the votes of two parliaments, one provincial the other municipal, and in the case of The Netherlands by the publication of a report abolishing the NPM-inspired autonomous status of many organizations with a public task. The paper concludes by suggesting reasons that led to the decline of NPM and concludes by offering a 'conceptual restart' of public administrative reform. This is based on a constructive mix between aspects of NPM and traditional administration, leading to a New Public Administration.

If the valuable elements of NPM are to be saved, some kind of understanding and accommodation is imperative with the role of the democratic process and 
the classic Weberian bureaucratic principles connected to it. A demonstration for this need for a restart will be made by the example of the Dutch government wide benchmark. A remarkable effort of showing the performance by organizations together responsible for more than half of all public expenditures, which still is not enough to satisfy the political process.

The end of NPM does not mean the end of the improvement of public organizations. Ignoring the classic political hierarchic way of getting things done is not an option, but neither is getting back to old mechanisms of power and distrust. There is need-an urgent need-for a conceptual restart. To do so, several elements should be considered. These have to do with trust and distrust, with building relations and rational concepts. We show how it can work - or at least we will give you the reader an A-B-C agenda for changing the public sector after the demise of NPM. Examples are found in the way the National Audit Office in The Netherlands had linked the different ways of showing yourselves responsive as a public organization. This means different ways of showing yourself responsive as an organization for different stakeholders. This starts with the parties in the democratic process, but it goes further than this. What does this mean for the future, by what rules of the game will we play? Some examples are given, a direction is indicated.

\section{The decline of New Public Management}

\section{NPM discredited}

No minister will deny it is important to deliver public services in time and in good order. No member of parliament will be against clear goals for a minister to attain. No citizen will say a government organization should be a mess. As such, no one will be against new public management. It would be like being against rain after a very hot day. So, at first sight, it is very strange that NPM and its consequences should get so much criticism. Still, that is very much the case. Not everyone will be familiar with NPM or what it stands for, but a great many people, including citizens, have an idea about the principles that are driving change in the government. Instead of embracing them, they greet them with cynicism and unbelief. We believe that this is more than an evidence of simple resistance against change. We believe that the principles behind NPM evoke a reaction that is fueled by distaste for a too rational, non political approach to people and organizations. Here we give you examples from two countries, Switzerland and The Netherlands. Neither of them lacks the resources to invest in something like NPM, but still the criticism is severe.

In Switzerland, the parliament of a province (canton) namely Basle, also home of the second biggest city of Switzerland, and the parliament of an important 
municipality of the canton of Zurich (biggest Swiss province), namely Dübendorf, have voted this year (2004) to stop all NPM related administrative reforms even though in both occasions NPM projects had been ongoing for several years. In The Netherlands, the cabinet and parliament support a report that calls for the end of the independent status of executive agencies, a firm legacy of NPM. The examples of the Swiss cantons and that of The Netherlands will be explained below, as examples of the decline of NPM. Here, it should be noted that these votes are more than a reaction from politicians towards civil service reform. It also reflects a general feeling in the populace that 'managerialism' has widened the distance between government and citizen; instead of bringing them closer together. Why else would parliamentarians vote something out of order that is basically no more than an acronym? Anyhow, by now we should be talking about No-longer-new Public Management.

\section{Swiss and Dutch examples}

Switzerland: a vote against something never attained. NPM was actively propagated to Switzerland by Professor Ernst Buschor in the early 1990's while he was still professor of management at St. Gallen University, the premier MBA school of Switzerland. Together with his student and later successor, Kuno Schedler, a prolific advocate and author on NPM, NPM principles were proposed to Swiss administrations as sine quo non to achieve a modern form of public administration. By 1998, consultants associated with then Professor Schedler proudly announced that 24 out of 26 cantons (provinces) had started NPM projects of small or larger scope but also already addressed reasons why some NPM projects in Switzerland have failed or were failing. ${ }^{1}$ Still, NPM seemed unstoppable despite clear indications of increasing difficulties with NPM implementation and strong reservations expressed by some leading academics, some expressing concerns about the incompatibility of NPM with existing administrative culture $^{2}$ and others raising objections to the political implications of NPM for Switzerland's federal and political constitution and its citizens' rights. ${ }^{3}$

Basle was not the first major canton to literally stop the NPM process in its tracks through parliamentary voting. Geneva, another important city and canton, also ventured into NPM projects in the mid 1990's but then also broke off the exercise despite the fact that the whole government consisted of a solid coalition of right wing parties who expressed full allegiance to NPM principles. Other NPM projects tittered, got completed in extremis or simply were not given sufficient political support to be continued. The most recent decisions by two parliaments, one cantonal, the other municipal, were tight races but still the verdict had to be taken seriously since they came after several years of public debate about NPM and after years of accumulated administrative experience with NPM type of administration. Hence, the decisions could not be considered the result of ignorance nor of accidental freak voting by local politicians. 
Example 1: Dübendorf. Dübendorf, the fourth biggest city of the canton (province of Zurich) is situated next to Zurich airport and is also the center of the Swiss Air Force Training Centre. Due to the proximity to the airport infrastructure and businesses, the economy is prosperous and people are in general well integrated in the larger Zurich region of Switzerland. Dübendorf started with a full NPM reform of its municipal administration in 1998. After several years of NPM reform guided by external consultants, the municipal council voted on 6th March 2004 against the continuation of the NPM reforms. The decision came after two years of evaluation and debate. The main reasons for cancelling the NPM reforms were a) NPM distraction was too costly (means did not justify ends), b) difference between strategic and operational task were not apparent, c) no improvement of efficiency, effectiveness nor of quality could be attributed to NPM reforms. ${ }^{4}$

Example 2: Basle. Basle is the second largest city of Switzerland, home of several large multinational companies (Novartis, Hoffmann La Roche, UBS etc.) and a university town. The canton of Basle started with initial administrative reforms in 1996, they moved to NPM pilot projects in 1997 in different parts of the cantonal administration. The government conducted an internal evaluation of the pilot projects, which were found to be positive. Subsequently, the government decided to extend NPM to all of the cantonal administration. The parliament however did not follow the proposal by the executive. The ensuing stalemate between government and parliament lasted until 14th January 2004 when the parliament finally voted on the issue and decided to cancel all NPM related reforms for the cantonal administration. Some of the stated reasons for canceling pertained to a) the costs for implanting and maintaining NPM were considered high without resulting in markedly improved administrative services, b) the new budgeting forms were found to be as confusing as the ones of the traditional administration, c) the assessment of internal costs too cumbersome, partially unclear and work intensive, and d) concerns were raised as to the possible negative impact of NPM on democratic practices and civil rights of citizens. $^{5}$

Netherlands: the end of independence from politics. The principles of NPM can be found within Dutch public administration from 1983 onward. Forced by an economic decline, a more market oriented approach came about. Deregulation and privatization set the tone - as ideas. In practice it took quite some time for these large movements to reach the Dutch shore, usually in a much mitigated form. From the beginning of the 1990's a wave of small initiatives were taken that together comprised all the elements of NPM. One initiative stood out. The municipality of Tilburg reorganized itself completely along the lines of NPM. This Tilburg-model became more well known outside The Netherlands than within it. Another example could be found in the way organizations and institutes with a public task reinvented themselves - until now. 
This July a report was published ${ }^{6}$ in The Netherlands about the status of 'zelfstandige bestuursorganen' in The Netherlands. These 'independent policy bodies' are responsible for the public tasks, but do not fall directly under the responsibility of a minister. ${ }^{7}$

Privatization was considered a step too far, but these bodies were set at a distance from politics. For example, ministers cannot be questioned by parliament on issues concerning these services. Under the influence of NPM, politicians did not trust themselves with the day to day responsibility for the deliverance of services. A so called 'interdepartmental review committee' (IBO), consisting of the ministry of finance and the interior, was made responsible for a review of the relation between the organs and the government. The ministry of finance dominated this review. The outcome: all organs should lose their independent status. There were a few exceptions (electoral board, etc.), but 'there is no fundamental reason for an independent status.' All arguments, mostly drawn from NPM, for an independent status, were put aside. Ministerial responsibility, so they argued is the leading principle and the rest is legal and business nonsense. This report is by far the most explicit rejection other than classical hierarchical responsibility that has ever happened in The Netherlands. The good side of the argument to refute NPM: government should take responsibility for it's own actions. If something is put at a distance, because your own political system cannot be trusted you should repair that system instead of creating legal or managerial barriers. Barriers that ultimately do not work.

Of course the review produced controversy. The civil servants from the ministry of the interior are angry, but they do not have the support of their minister. The people at the zbo's are worried too. They have put large ads in the papers with all their performance indicators, trying to show that they are much more transparent than the departments themselves. But they seem to be waging a losing battle. The only weapon they have is delay. NPM arguments are truly counter productive now.

\section{The reasons why}

There is more than one factor in the decline of NPM as a driving force behind change in the public sector. In 'reinventing government, ${ }^{8}$ the book at the start of the movement, there is a metaphor about civil servants working together as rowers in a boat. Well, that boat is in disarray. We give two main reasons why. The first is that the proponents of NPM have underestimated the culture clash that lies underneath a change towards the principles of NPM. ${ }^{9}$ The second is of a more structural nature. One cannot overnight change the principles of government. Principles that have been taken from the writings of Max Weber and seem to be more robust than many people from the managerial revolution expected. 
Five reasons for a culture clash:

1. NPM suffers from a fundamental misunderstanding between a value driven and an effectiveness driven approach to government. The democratic process has more goals than the delivery of services. Perhaps most of all it is about the transfer of values. NPM was a reaction to a perceived lack of effectiveness of the way government works. The rejection of NPM is due because it has never taken root in a social movement representing social values, and as far as it does so, those market-oriented values provide inconclusive direction. They lack for instance aspects like legality and, up to a degree, democracy as leading values for governmental action in a 'state founded on law. ${ }^{10}$

2. A citizen is not a client, a government not a company. Osborne and Gaebler said that 'putting the customer first' is an essential goal for new public management. To a degree this still needs to be said. Government organizations are always in danger of forgetting those for whom they are working. So there is merit in the metaphor of citizens as customers. But the metaphor is a limited one. Citizens have duties that customers do not. And ultimately it is the task of government to balance conflicting demands against each other. This means that at most birthday parties it is not a popular thing to say that you work for the government: somebody always feels wronged. Yet, this is at the heart of the public challenge - and is the reason that working for the public sector is so much more interesting than working for a company.

3. NPM requires a long term commitment. That is hard to do in a short term world. In the Dutch example, much of the critics against the independent organizations was and is based on research results that indicated that five years after the decision to put the organization at a distance, service delivery had not significantly improved. The top salaries of the directors were most definitely improved. This, of course, gives rise to a lot of cynicism and plain envy. However, it looks like five years has been too short a time to adequately measure the changes that came about. It is only now, almost ten years after most decisions have been taken, that significant change seems to have come about. ${ }^{11}$ Politicians, for very sound reasons, usually cannot wait that long. Depending on the political culture of a country and the role of for instance the media, a long term perspective - say, more than one election-can not be sustained. The claims for a quick success then get in the way of real achievements in the organizations where NPM is introduced.

4. NPM is in a way a luxury. It is a western philosophy that more often than not raises false hopes in government organizations that lack fundamental resources. Every change costs effort and money. The rewards of an investment may lie many years in the future. Is NPM worth the effort? This is a relevant question for every country, but it is more urgent in countries that lack basic resources. Revamping a government in a more customer-oriented style can bring great benefits, but will it be enough to win the trust of the 
general audience? There are no real examples that it does. However, the reverse is also not true. The strength of NPM is the external orientation that it brings. In many cases, not investing in NPM-elements will mean not investing in change.

5. NPM has been used as too much of a stand alone method. The mistake was that it was not used with more consideration for the context in which it was being applied. This is a context of a larger economic and social-political environment. Economic realities were ignored, like the effect you get when prices for public services suddenly become visible when services are privatized or simply published. Social and political realities reassert themselves when cost-benefit ratios are ignored in favor of wider considerations. And it also ignored the realities of a public sector that more often than not is determined by factors like professionals attitudes. Promising better management does not help when every action the management takes seems designed to erode the trust of professionals, for instance in health care. ${ }^{12}$ So far, the evidence is that NPM leads to more consultation of customers, professionals and employees, but not to a more effective performance. ${ }^{13}$

Four reasons why Weber was not a manager:

6. NPM denies the benefits of hierarchy. NPM challenges the Weberian hierarchal model, in as much it accentuates results, and seems to care less about how they are achieved. Its emphasis on the empowerment of customers and employees seems to cut right through the heart of the traditional model for the organization of government. NPM follows the managerial way of doing things, and that means it puts process above hierarchy. ${ }^{14}$ Hierarchy has many drawbacks. In the interplay between legality and democratic responsibility in a government setting it produces bureaucracy, and bureaucracy is almost always seen in a negative light. Yet, time and again, the Weberian principles reassert themselves, and this for very sound reasons. Predictability, accountability and legality thrive under true Weberian bureaucracy and these elements are in more demand than ever. If NPM cannot deliver on its promises, as seems for instance the case in Sweden, ${ }^{15}$ the call for a more classic Weberian state is eminent. It seems to be true: in government we like to think radical and act conservative.

7. NPM is based on trust. The many incidents and doubts about the integrity of civil servants erode that trust. The introduction of NPM in a government organization does not mean that society will stop making demands on that organization, or that within that organization suddenly everything will start working smoothly. Accidents will happen. Incidents will be made. Organizations and its leaders will be asked to account for failures and the blame game will be played. In The Netherlands, it is proven that the net result is often that the so called 'independent' organizations have to spend more time answering questions from central government than they did before they were made 
independent. A big communication budget does not help when trust is undermined by a negative image in the press.

8. The management concepts behind NPM are too instrumental or used in a too instrumental way. The problem with much of the concepts and models that are developed by the thinkers of this world is not the concept or the model itself. It is the way they are applied: too direct and too instrumental. Time after time, it is shown that the right attitude, in combination with improved skills, is required for a successful application of modern management concepts like NPM. ${ }^{16}$ The extra danger in a government environment is that the concepts and models are applied the way laws are applied: strict and without exceptions. The experience with Baldridge and EFQM award schemes show that it is great leadership and people skills that make the difference.

9. The paradox of performance indicators. One of the great drawbacks of a result oriented style of governing is that it produces numbers. Not that numbers in themselves are wrong, on the contrary. As the saying goes: what is measured gets done. The problem is that there are soon too many numbers and that the numbers start getting misused. Instead of focusing on a few chosen indicators, as many indicators as possible are being used and followed through time. This, in a usually false assumption, that these represent the truth about society or government performance. In other words: performance indicators soon get perverted. ${ }^{17}$ One of the authors has been responsible for the introduction of citizen's charters in The Netherlands. He discovered that the process of the making of a charter, including the performance indicators, was much more important than having the charter. The indicators that were actually there on the realized charter soon got either ignored or misused. ${ }^{18}$ The lesson: performance indicators are necessary means to an end. To create a true performance indicator you need to be careful with the way you gather and use numbers. NPM proponents were carelessly naïve in the way they promoted the unlimited use of numbers as performance indicators.

\section{An unfulfilled promise}

The criticism leveled at NPM is nothing new. From the very start of its existence scholars and others leveled charges against NPM as either too superficial or too market-oriented. This did nothing to stop the rise of NPM. In some form or other it has been applied in a great number of countries and elements of it can be found in almost every country. What is new, is that the measures taken under an NPM-heading are now actively being scaled back or even undone. What worries, is that the way NPM is being undone, is often based on either some misunderstanding about what NPM can accomplish or simply a lack of time to give the culture change behind NPM a realistic chance. The reasons mentioned 
above, all imply that NPM is not an easy thing to achieve. Still, the fact that NPM has not fulfilled its promises does not mean that the underlying reasons why NPM came into existence have disappeared. Will service delivery improve when NPM is abolished? Will politicians deliver more on their promises after the election? Not very likely. The best thing to be said is that the pretence is gone.

\section{Restart}

More than trust and rationality

The need for a conceptual restart is obvious. But how do you prevent falling into the same pitfalls? Maybe NPM was too rational an approach for the public sector. Considerations of power and distrust did not come into it, other than that its irrationalities had to be overcome. Ultimately, the drive for 'good government' or a 'civil society' is not at odds with a drive towards a more result-oriented, customer friendly government. However, trying to combine these goals takes time, meanwhile reflecting a real culture clash between different visions of how government should work.

What is needed is a combination of more traditional public virtues and modern management approaches. Perhaps that means marrying Weber and the world wide web, but even if we try for a concept a little less complex, something new is in order. Later in this text this will be translated in a combination of vertical hierarchy and horizontal responsiveness. However, first we must make a sidestep before offering another model to the world. No model works unless the dynamics behind it are understood.

For this we present a scheme in which on the vertical axis trust and distrust are the dominating factors and on the horizontal axis the rational and the irrational (or better: emotional) are the dominating factors. In other words: as contrasting words as we could formulate. But very important words. In the resulting matrix, different approaches to change take their place.

We look upon NPM, and its constituent elements like TQM and HRM, as an example of a systematic approach, born from a believe in rational arguments and a basic trust in the positive motivation of people in organizations. Who can deny the logic of NPM? Well, many people have done so. For instance because they believe this new concept will not change a thing, just like all the other concepts resulted in nothing. Distrust of the rhetoric of change and the emotion of 'not again' combine to create often lasting resistance against change. ${ }^{19}$ Others see the logic behind NPM, but distrust where it is leading to. Either for ideological reasons or because of more personal ambition, they take an approach towards NPM that is filled with considerations of power and position. And then there is the line taken by those who do not care one way or another 


\begin{tabular}{lll} 
Rational & power & $\begin{array}{l}\text { systematic } \\
\text { relational }\end{array}$ \\
\cline { 2 - 3 } Emotional & resistance & Trust
\end{tabular}

Figure 1. Trust and rationality.

about NPM, but like the fact that working for or against it brings them in closer contact with the people that matter. They think: it is not what you know, it is who you know (Figure 1).

We state that NPM has been brought to government as a straight jump to a systematic approach. The resistance against it was too much seen as a product of emotional resistance and trust. We believe that a systematic approach is only possible when it takes account of-and is built upon-either consideration of power or of relationships.

Much more could be said about this. Our main point is this. A restart for NPM must take into account not only what is in it, but also how it is done. The dynamics of change have been ignored in the implementation of NPM. The proponents of it never succeeded enough in convincing that implementation of NPM was not just in the interest of those who were doing the introducing.

\section{More congruence between Public Administration and larger policy mix}

Administrations are embedded in the larger context of our societies. Reforming administration in vacuum cannot be sustainable. If the larger policies are in opposition to the administrative structure, conflict will emerge. On the other hand, if the public perceives incongruencies between what the executive promises (administrative reforms) and what parliament wants (laws), conflict will be inevitable.

If the public perceives incongruencies, reforms will not hold. For example, CLAD's (1998) document on New Public Management for Latin America states: ${ }^{20}$

Only by improving their capacity to govern may the State apparatus help balance the three major Latin American concerns, which might as well be repeated here: the consolidation of democracy, economic development and better distribution of wealth (p. 50)

Government leaders who propose implementation of NPM by arguing that state budgets need to be cut and performance of civil servants need to be improved while at the same time emphasizing privatization and elimination of social programmes run into difficulties of credibility. It is one thing to improve administration performance, but another to privatize and to reduce wealth distribution. Citizens will not buy both in one package. It is wrong and unethical 
to blame civil servants for being "resistant" to change if the change means more work, lower salaries, less recognition and no more job security.

Similarly, if government link administration reform with privatizations, resistance in the public at large might increase due to the fact that the benefits of suggested privatization are not self-evident and also due to the fact that privatization often meant transfer of a public monopoly to a private monopoly without due returns to the state.

John Fawkner, Head of International \& European Affairs at Transport for London, ${ }^{21}$ recently summarized the plus and minuses of rail privatization based on several years of experience in the United Kingdom. While seeing benefits of privatizing in regards to new investment in rolling stock, some investment in infrastructure and reductions in maintenance costs, he also warns of:

- decline in critical maintenance standards

- decline in service standard due to train staff shortages and poor maintenance

- safety impaired by separation of responsibilities for track and trains

- difficult ties in getting work done to meet train operators requirements

- diversion of effort in legal disputes

- contract takes precedence over actual passenger and operator requirements

- major management errors (new trains held $2+$ years)

- large increases in controlled fares

- cost of engineering work doubled or trebled

- west Coast main line (cost $\times 6$ )

- failure of train track: massive liabilities (ca 14bn Euros)

The long list of downside factors needs to be taken into consideration before governments venture into privatizations. In the same token, NPM reforms might further exacerbate such dangers, if for instance a NPM led government does not retain sufficient policy competence within its own regulatory range, but instead decides for instance to outsource regulatory oversight and supervision.

\section{Examples}

We give here examples of initiatives that have a clear NPM-background, but still take care to stay within the bounds of public sector rules and sensibilities. The examples are from the Netherlands.

Government wide benchmarking in The Netherlands. In 1999 the Dutch newspapers were full of a tremendous cost overrun at the public organ for education benefits (IB-Group). Both the ministry for education and the organization had a hard time explaining themselves. After some consideration, both came to the conclusion that what they needed was more comparative information. The ministry wanted to show that the mishap was not to be tolerated, but still mild compared to mishaps in for example the public sector. 
The organization wanted to show that, apart from this mishap, they were doing many other things right. So they started a benchmark effort.

The benchmark is by now (2004) in its third round, the first one having been a try-out. The organizations involved are responsible for more than $40 \%$ of all public expenditures in The Netherlands. Taken together, the organizations provide services for all Dutch citizens, involving more than 100.000 employees. ${ }^{22}$ The benchmark is structured along the lines of the Dutch version of the EFQMexcellence model. ${ }^{23}$ The so-called 'result areas' are filled with about a 150 performance indicators, mostly to do with front-office activities. The organizations compare themselves against each other, with best result, worst result, etc. More important is that each organization has to open up their best practices for each other and visiting each other. The result areas are checked by doing audits at each other. Teams from different participating organizations visit a participant and check the validity of the indicators, exchanging experiences along the way. The main goal, as stated by the participants themselves, is to learn from each other-and it seems that they are really doing so. All in all, these are classic things to do when doing a benchmark.

But when one looks at the size of the effort and the sensitivities involved, this is an impressive effort within a public sector context. Perhaps the most interesting thing about this benchmark, certainly within the context of this article, is what they do with the results of the benchmark. Those results are quite stunning, taking into account the enormous diversity of the organizations involved and their different tasks and contexts. Two questions had to be addressed: what to do with the outcomes for the individual organizations and what to do with the overall outcomes? It was decided that there would be no publication of individual outcomes. There would be a report with general outcomes, but they would be published anonymously and would receive as little attention as possible. This was not done out of a need for secrecy, the documented stated. If necessary, the data could be given to, for instance, to members of parliament on request. Basically it was done to restrain the participants themselves from showing off with the results. The process of the benchmark was considered to be more important than the immediate results of the benchmark.

This restraint in the use of the results of the benchmark is not always easy. For example, the outcomes of the benchmark have to some extend been used in the debate about the independent status of organizations with a public task (see 1.3). These results, however, did not make the slightest impression on the writers of the review. All they said was 'that it was nice to know that some of the organizations consider it an honor to improve their service.' In other words; the results were neither credible nor persuasive. The distrust between central government and independent organizations was too pervasive for that. This is a pity, to be sure. Why is it that this is no longer persuasive to a government, when it should be grateful that something is working? Central government is not exactly successful in showing its performances either. But it also gives rise to two important conclusions. The first is that it is not about immediate results. 
Trust must be built and cannot be demanded. The second is that organizations should start initiatives like this for more than just the satisfaction of the central actor. It is with these two conclusions, and especially the latter, that we step into the future.

\section{The future}

\section{Steps to be taken: $A$ B C}

Having established the needs for a restart, and indicated different routes towards that restart, the question remains what the future will hold if such a restart is made. Here we make a first effort.

The danger is of course that we want too much of a good thing. The combination of too many elements within one model may make matters worse and not better. These authors have much sympathy for those writers who aim for simplicity instead of more complexity. ${ }^{24}$ However, if a model is 'a simplification of reality' then a model for the public sector has to deal with a lot of reality. The complexity of the public sector and its processes must be reflected in that model. ${ }^{25}$ Must it? Here we start with a 'simple' A-B-C. What the public sector needs is Action, Belief and Consistency.

\section{Action}

Action in more than one direction. This means:

- activities that touch all the elements of the public sector system

- accountability in more than one direction

\section{Belief}

Most of all a belief in the need for a better public sector, involving:

- a strong public sector ethic

- a meta-approach of public sector management, combining both political, policy and practical considerations

\section{Consistency}

From a conviction that only a consistent approach gets results, we state the need for:

- constant reminders of the outside world

- continuous improvement above radical change 
This is all more an agenda for the future than a new model. But it could work. Because of constraints on our time, only one of these A-B-C elements will be worked out here.

\section{Accountability in all directions}

NPM demanded a focus on the outside world. The reaction against NPM demands a reassertion of hierarchical truths.

Like in other countries, there is in The Netherlands a strong national audit office. It is a truly independent organ of the state, and very active in its search for evidence of unlawful or ineffective expenditures. It does so from a clear Weberian philosophy of 'ministerial responsibility.' All activities in the public sector should be accounted for within the framework of the responsibility of a minister for a certain policy or budget. However, this approach got more and more criticism from organizations and institutes that did not care so much about the accountability towards some distant minister as they cared about accountability towards patients, clients and other representatives of the civil society. In other words, the framework of the Audit Office did not support the idea that the public sector needs to deal with different stakeholders. Especially the effort that many organizations were making in the field of quality management went unnoticed by the audit office. Worse: the activities done for the audit office often stood in the way of the efforts that were done under the aegis of a Total Quality Management approach. Listening to this criticism, the Audit Office tried to develop a frame work into which were put all the different goals, instruments and approaches that are in use in the public field. ${ }^{26}$ They then tried to put this in a framework of vertical accountability (parliament at the top, citizens at the bottom) and horizontal accountability (external stakeholders like a board of overseers, and the management and employees of the organization themselves). Ultimately, they refuted the idea of either vertical or horizontal accountability, stating that the so-called horizontal forms of accountability could only be considered when in support of the ministerial responsibility. In other words; the responsibility towards different stakeholders can never replace the responsibility towards the minister. The Audit Office stays stubborn. Nevertheless, it is onto something. Here the scheme of the Audit Office translated into English (Figure 2).

Activities on all 4 axis activities must and will be deployed. It is not enough to satisfy the demands of parliament and central government of the citizens themselves. Different stakeholders need different approaches.

This provides a model for the way public organizations will employ actions in all directions and account for them as well. A sort of ' $360^{\circ}$ accountability' can be foreseen, with websites with interactive features showing different ways of responsiveness towards different stakeholders. The elements of NPM will be in there, along other elements. The demands of the democratic process will always be leading, but they will never be all inclusive. It is up to the public organizations 


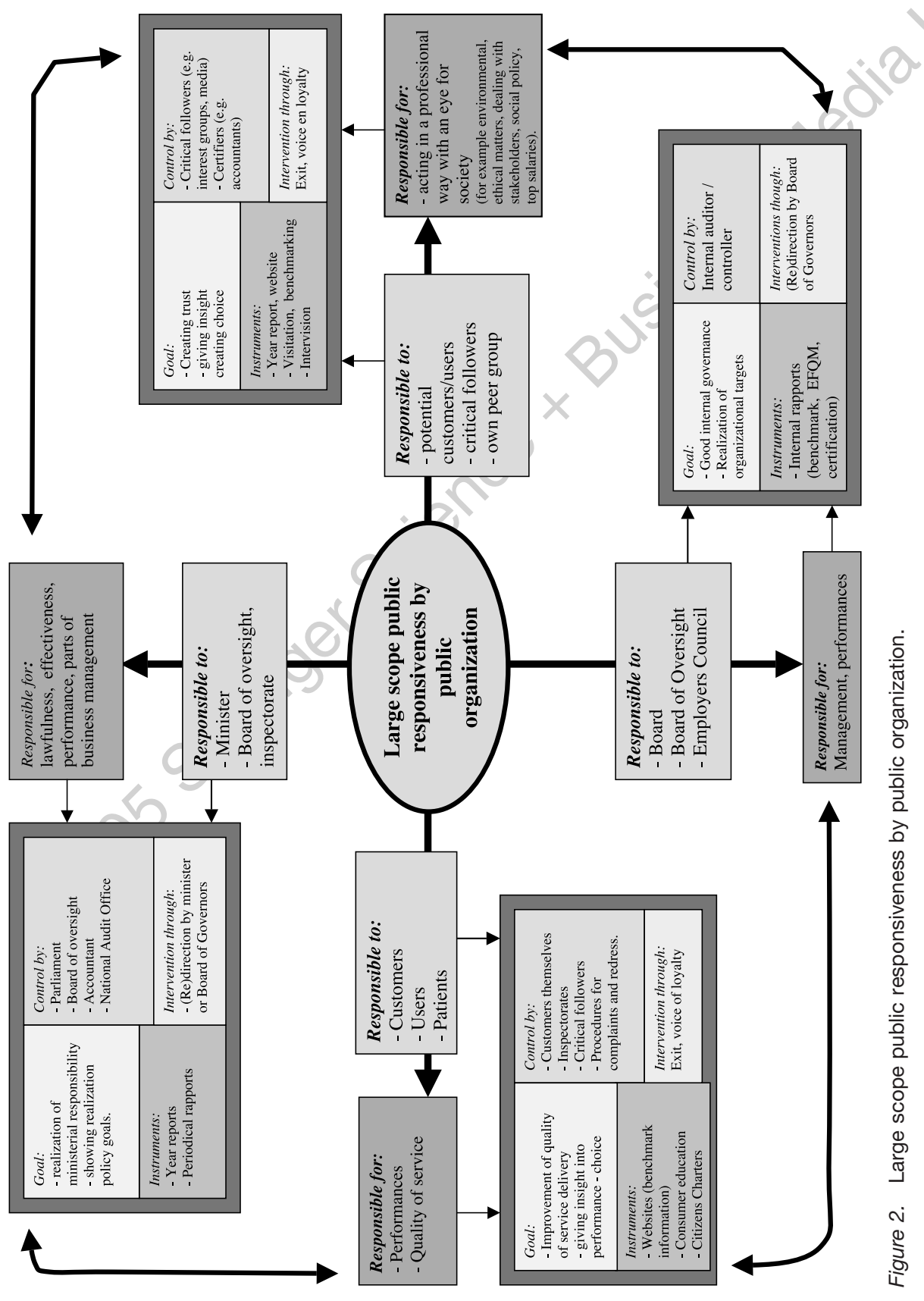


to play this right. Take for instance the participants in the Dutch benchmark mentioned earlier. They will most certainly use the existence of the benchmark as an argument in their favor, but will not use the specific results. The results that concern the average customer will if possible be published, just like the managers and employees of the organizations will know and use an extensive part of the benchmark. The board of overseers will hear the part that is relevant for them, etc. Manipulation? You could call it that, if the intention is to hide results instead of showing them. But organizations that work from a strong public ethic and have their eyes on the future will think twice before doing so. Instead, they will seek the borders of transparency.

Rules

After having described the decline of NPM and stated a need for a restart, we have subsequently formulated an agenda for that restart and given an example in the form of a new approach of accountability. What remains is the need to postulate some rules for the implementation of it all. As described, there are a lot of factors involved in the successful implementation of a model or a policy. The fact that an approach is attractive in its rationality somehow makes the need for that even more so.

In closure, we formulate some short 'rules of conduct.' These rules, it must be said, are nothing new. At least, we hope they are not. This is not yet the time to work with a whole new set of rules. The best of NPM should be preserved and continued. Work should be done to connect them with old realities of the public sector. And both NPM and classic realities should be taken many steps further in the direction of the agenda. So what we give here are some old truths about implementation.

1. Problems must be solved, not diverted. In the end, NPM was too much about form and not enough about substance. After the resistance became too much, too often the words of change replaced change itself. A little less rhetoric and a little more attention to implementation is in order.

2. Good management cannot replace good policy or vice versa. A managerial approach to the delivery of public services is still very much needed. Good management should be recognized as a profession in itself. Yet a manager should accommodate to policy needs, if he or she is to work in a public environment.

3. Reliability is as important as responsiveness. Showing yourself responsive to the outside world is more important than ever. People and organizations in the public sector should realize that this is a contract that involves many stakeholders in a more and more interactive way. However, the public sector has a 'bias' towards reliability. Over and over a public sector organization must show itself reliable or trustworthy in the eyes of the public. The 
organization that is the most successful in the implementation of the agenda is the organization that manages to combine responsiveness with reliability.

4. Let performance speak louder than incidents. It seems like every organization in the public sector is sooner or later hit by an incident that puts it in the eye of political and media storm. When an incident like that hits the organization, it is usually too late to come with all kinds of reports showing how well you have otherwise done your job. It should be the other way around. Work on a continuous base on your performance and the communication of it. Some incidents can and should be prevented, but not all. An organization that works on its performance is less vulnerable for the occurrence and aftermath of these incidents.

5. Trust is the key. There is something of the 'quick fix' about NPM. The public sector is ultimately not about quick fixes, no matter what promises are made in election time. Trust will not be gained by concepts or instruments, if the right attitude and public ethic is not there. If it is there, and in all nations examples can be found, then the public will rely on them more than on any other in society.

\section{Notes}

1. "NPM today - and why some projects fail: interview of Professor K. Scheduler," (English translation), WOV/LOS Bulletin, Lucerne, 7th December, 1998.

2. "The learning administration and its leadership culture: a discussion with Professor Werner Müller," (English translation), Public Management, 3/2002, Federal Personal Office, Berne, 1998.

3. Peter Knoepfel, "Le 'New Public Managemenet: est-ce la panacée?," Swiss Political Science Review, 1(1), 133-138, 1995.

4. "Abbruch des NPM Versuchs in Dübendorf," NZZ, 6th April 2004, Zurich; Message to municipal parliament by city council to end NPM, Nr. 84, 28th August 2003. Dübendorf.

5. Background document by Basle government to parliament on proposal to vote law on NPM, 19th September 2003, Basle.

6. Werkgroep verzelfstandigde organisaties op rijksniveau-Een herkenbaar staat: investeren in de overheid. (Government working group on independation-A recognizable state: investing in the government.). Ministerie van Financiën en Binnenlandse Zaken en Koninkrijksrelaties. Interdepartementaal Beleidsonderzoek 2003-2004, nr. 1. Den Haag, July 2004.

7. They could be called 'executive agencies,' but with a more autonomous or independent status. Depending on how you count, there are about 400 at central level in The Netherlands and many more at the decentralized level.

8. David Osborne and Ted Gaebler-Reinventing Government. How the Entrepreneurial Spirit is Transforming the Public Sector. Addison-Wesley Publishers, New York, 1992.

9. Süleyman Sozen and lan Shaw-The international applicability of "new" public management: lessons from Turkey. International Journal of Public Sector Management, vol. 15, number 6, 2002, p. $475-486$.

10. Nico Nelissen (ed.) —Renewing Government. Innovative and Inspiring Visions. International Books, Utrecht, 1999.

11. Measuring the real rise in performance will be difficult still. Arguments could be made that it is the push of information technology that is the real engine behind improvements in performance. Our argument, based on many EFQM-assessments, is that this rise in performance could not have 
been made without an overall rise in improvement, and that the chances for this to occur increased with the relative stability of independence.

12. Ruth Kowalczyk-The effect of new public management on intensive care unit staff. International Journal of Public Sector Management, vol. 15, number 2, 2002, p. 118-128.

13. Sylvia Horton-Participation and involvement-the democratization of a new public management? International Journal of Public Sector Management, vol. 16, number 6, 2003, p. 403-411.

14. In this NPM resembles the post modern approach of government. It differs from this approach in the sense that NPM is in favour of a much more rational approach to government.

15. Per Skålén-New public management reform and the construction of organizational identities. International Journal of Public Sector Management, vol. 17, number 3, 2004, p. 251-263.

16. John Dixon, Alexander Kouzmin and Nada Korac-Kakabadse - Managerialism - something old, something borrowed, little new. International Journal of Public Sector Management, vol. 11, number 2, 1998, p. 164-187.

17. Hans de Bruijn-Performance measurement in the public sector: strategies to cope with the risks of performance measurement. International Journal of Public Sector Management, vol. 15, number 7, 2002, p. 578-594.

18. Drs. D.P. Noordhoek en Drs. M.A. Muntinga. Kwaliteitshandvesten. De kracht van kwetsbaarheid (Citizens Charters. The strength of vulnerability). Kluwer, 1997.

19. Francis Fukuyama-Trust. The Social Virtues and the Creation of Prosperity. Penguin Books, 1995.

20. A New Public Management for Latin America," CLAD, Caracas, 1998.

21. John Fawkner, "The liberalizsaton of transport in the UK: some lessons form across the Channel," presentation given at the conference in Barcelona, 28th June 2000 titled "Present and future of services of general economic inerest in the EU."

22. The numbers tell only part of the story. The benchmark involves for instance the whole of the prison system, and the police of Amsterdam, organizations where the total expenditure is not a significant indicator for size or performance. Source: Rijksbrede Benchmark Groep-Benchmark Uitvoeringsorganisaties 2004. Samenvattend rapport. (Government wide Benchmark GroupExecutive summary 2004) Amstelveen, May 2004.

23. In fact it concerns a very special translation of the EFQM-criteria by the Dutch Quality Institute, the INK. For a translation of the Dutch INK scan: D.P. Noordhoek: www.northedge.nl/articles.

24. See for instance: Margaret J. Wheatley and Myron Kellner-Rogers-A Simpler Way. BerretKoehler Publishers, San Francisco, 1996, and Edward de Bono-Simplicity. Viking Books, 1998.

25. One of the reasons for the fact that in The Netherlands the EFQM-model is much more popular than the ISO 9000 certification scheme is that it seems to give a better reflection of the public sector realities. Even so, there is a lot of criticism of the presumed rigidities of the model.

26. Algemene Rekenkamer-Verbreding van de publieke verantwoording. Ontwikkelingen in maatschappelijke verslaglegging, kwaliteitszorg en governance. (Government Accounting OfficeBroadening of public responsiveness. \pm Developments in social accountability, quality approaches and governance.) The Hague, May 2004.

\section{References}

Osborne, D., and T. Gaebler. (1992). Reinventing Government. How the Entrepreneurial Spirit is Transforming the Public Sector. New York: Addison-Wesley Publisher.

International Institute of Administrative Sciences. (2001). "Governance and Public Administration in the 21st Century: New Trends and New Techniques." Proceedings. Twenty-fifth International Congress of Administrative Sciences. Athens, July.

Nelissen, N. (Ed.). (1999). Renewing Government. Innovative and Inspiring Visions. Utrecht: International Books. 
Saner, R. (2002). "Quality Assurance for Public Adminstration: A Consensus Building Vehicle." Public Organization Review 2(4), 407-414.

Drs. Peter Noordhoek has played a major role in introducing quality concepts for the public sector in The Netherlands. He introduced Citizen's charters to The Netherlands and adapted the EFQM model to the public sector. He is partner of The Dutch Quality Institute, chairman of the government section of the Dutch Quality Association and member of the board of the Dutch Association for Inspection, Oversight and Evaluation. Recently he served as chairman of the government wide benchmark (RBB). $\mathrm{He}$ is member of the Advisory Board of the International Journal of Public Sector Management

Dr. Raymond Saner is a longtime member of the International Institute of Administrative Sciences in Brussels and of its Swiss section in Berne. He is co-founder of CSEND, a Geneva based Nongovernmental Research and Development Organisation. Dr. Saner was member of the international working group which drafted the new ISO 10015 Quality Standard on Education and Training (1996-2000) and was the initiator and member of the Swiss working group which drafted the new Quality Guideline for public administration titled "Maîtriser le changement dans le secteur public par le management de qualité" (Swiss Quality society, 1996-2000). 